\title{
ANALISIS BIAYA PEMANENAN KAYU BULAT SISTEM KEMITRAAN HPH - KOPERASI DESA DI KALIMANTAN TENGAH
}

\section{An Analysis of Forest Harvesting Cost of Forest Concession in Collaboration with Community Wellfare Cooperative in Central Kalimantan}

\author{
Oleh/By: \\ Zakaria Basari
}

\begin{abstract}
To minimize illegal logging in natural production forest, one of concession forest in Kalimantan has initiated to do a joint bussines logging with a community wellfare cooperative. The aim of the study was to measure productivity of extraction, operation cost, joint bussines income, investament and income of KoperasiDesa.

The observation area was located at PT Tanjung Raya Intiga (PT TRI), Barito Hulu Puruk Cahu Forest District, of Central Kalimantan Province in 2001.

The results showed that logging production achieved was $892,9 \mathrm{~m}^{3}, \log$ extraction productivity $99 \mathrm{~m}^{3}$. hm/hour, operation cost $R p 14,227 / \mathrm{m}^{3}$, logs selling revenue $R p 31,235,950,-$, investment cost Rp 2,901,017.- and cooperative income $R p$ 28,901,017.-.

The financial income was distributed to local community (34\%), wages for cooperative bussines managers (29\%), village contribution (4,5\%), administration fee for cooperative (5\%) and government officers $(27 \%)$.

The local people and the forest concessioners could share the benefit of cooperation in natural production forest management.
\end{abstract}

Keywords: Operation cost, logging, joint bussines, cooperative

\section{ABSTRAK}

Sebagai salah satu cara untuk menekan berkembangnya kegiatan ilegal loging di hutan alam produksi, sebuah perusahaan HPH di Kalimantan Tengah mengadakan usaha kemitraan dibidang pemanenan kayu bulat dengan Koperasi Desa sekitar hutan. Tujuan penelitian ini adalah untuk mengetahui kinerja kemitraan HPH dengan Koperasi Desa meliputi aspek produktivitas penyaradan, biaya operasi, pendapatan Koperasi Desa serta penyaluran keuangan hasil usaha tersebut.

Penelitian dilaksanakan di areal HPH PT Tanjung Raya Intiga (PT TRI) wilayah kerja Cabang Dinas Kehutanan Barito Hulu Puruk Cahu, Dinas Kehutanan Propinsi Kalimantan Tengah pada tahun 2001. 
Hasil penelitian menunjukkan, bahwa jumlah volume kayu produksi yang dikeluarkan oleh Koperasi Mitra Desa mencapai $893 \mathrm{~m}^{3}$. Produktivitas kerja penyaradan kayu rata-rata mencapai 99 $\mathrm{m}^{3} \mathrm{hm} / \mathrm{jam}$. Biaya operasi pengeluaran kayu rata-rata mencapai $\mathrm{Rp} 14.227,4 / \mathrm{m}^{3}$. Hasil penjualan kayu memperoleh Rp 31.235.950,- sedang biaya investasi Rp 2.901.017,-. Sehingga pendapatan Koperasi mencapai Rp 28.901.017,-. Pendapatan uang Koperasi Desa tersebut disalurkan kepada warga masyarakat desa sebesar $34 \%$, pengurus koperasi $29 \%$, kas dusun $4,5 \%$, administrasi koperasi $5 \%$ dan aparat $27 \%$.

Hasil kajian menunjukkan, bahwa pengusaha lokal dan masyarakat sekitar hutan sudah mulai merasakan adanya keadilan dalam menikmati keberadaan hutan alam produksi. Dengan demikian, kerjasama pengelolaan hutan alam yang baik yang ditunjang dengan iklim kemitraan yang kondusif terbukti menguntungkan ke dua belah pihak yaitu pihak konsesi hutan dan Koperasi Desa. Sistem pemanenan hutan dengan cara ini perlu dikembangkan untuk daerah lainnya.

Kata kunci: Biaya operasi, kayu bulat, koperasi, usaha kemitraan

\section{PENDAHULUAN}

Ada tiga pilar utama yang perlu diperhatikan dan dipertahankan dalam melaksanakan pengelolaan hutan alam produksi, yaitu : (1) Kelestarian fungsi produksi, (2) Kelestarian fungsi sosial dan (3) Kelestarian fungsi konservasi. Jika dari ketiga kelestarian fungsi tersebut salah satunya tidak ada, maka tidak bisa dihindarkan pengelolaan hutannya bukan semakin maju tetapi sebaliknya justru akan semakin menurun.

Pada era Orde Baru pengelolaan hutan alam masih dititik beratkan kepada kegiatan produksi, seperti tergambar pada angka ekspor kayu gergajian dan kayu lapis masingmasing US \$ 14,376,348 dan US \$ 2,920,289,376 (Departemen Kehutanan, 1992). Di samping itu penyerapan tenaga kerja cukup besar, terbangunnya infra struktur jalan yang menembus daerah pedalaman (remote area) yang semuanya itu sangat memberikan kostribusi yang berarti untuk memajukan ekonomi nasional. Namun kelestraian fungsi konservasi dan fungsi sosial kurang diperhatikan sehingga dampaknya dapat dirasakan sekarang, yaitu kerusakan hutan yang semakin luas, maraknya ilegal loging, kebakaran hutan dan lain sebagainya. Informasi terakhir dari Ditjen Pengusahaan Hutan menyebutkan bahwa dari seluas 52 juta ha hutan produksi di Indonesia dalam kurun waktu 10 tahun telah terjadi penyusutan sebesar 32\% atau rata-rata 4,2 juta ha per tahun (Anonim, 1999 ).

PT Tanjung Raya Intiga (PT TRI) adalah salah satu HPH yang beroperasi di Propinsi Kalimantan Tengah yang cukup peduli terhadap masalah tersebut dan bermaksud melaksanakan SK dari Kepala Dinas Kehutanan Propinsi Kalimantan Tengah No 552.4/ 833/4/05/VI/2001 perihal Pembinaan Masyarakat Desa Hutan (PMDH). Sehubungan dengan itu dilaksanakanlah kerjasama tebangan antara PT TRI dengan Koperasi Desa setempat sebagai realisasi pelaksanaan proyek PMDH untuk dua desa dekat HPH tersebut.

Dewasa ini, hasil penelitian tentang usaha kemitraan pemanenan kayu bulat dari hutan produksi antara pengusaha HPH dengan masyarakat desa hutan di Indonesia belum banyak diketahui.

Tujuan penelitian adalah untuk mengetahui kinerja pelaksanaan usaha kemitraan di bidang pemanenan kayu bulat antara pengusaha HPH dengan Koperasi desa serta biaya operasinya. 


\section{METODA PENELITIAN}

\section{A. Waktu dan Tempat}

Penelitian dilaksanakan di HPH PT TRI yang berlokasi di Cabang Dinas Kehutanan Barito Hulu Puruk Cahu, Dinas Kehutanan Kabupaten Tk II Barito Hulu Tb Lahung, Dinas Kehutanan Propinsi Kalimantan Tengah. Penelitian berlangsung pada bulan September sampai dengan bulan Oktober 2001.

\section{B. Bahan dan Peralatan}

- Kertas buku dan HVS tally sheet, peta kerja HPH dan peta situasi yang ada di sekitar hutan.

- Meteran, kompas, gergaji mesin, traktor, stop watch, cat, golok dan kamera.

\section{Kegiatan yang Diteliti}

- Aspek teknis meliputi pengukuran panjang jalan sarad dan perhitungan produktivitas penebangan dan penyaradan kayu bulat

- Aspek ekonomis meliputi perhitungan biaya operasi penebangan dan penyaradan kayu bulat

- Aspek sosial meliputi wawancara tentang keadaan koperasi desa dan warga masyarakat sekitar hutan.

\section{Prosedur Penelitian}

- Melakukan pembatasan areal kerja yang dialokasikan untuk usaha kemitraan

- Melakukan wawancara dengan operator chainsaw, traktor dan staf perusahaan HPH dan pengurus koperasi mitra desa serta petani warga desa

- Menghitung jumlah dan volume pohon yang diproduksi di TPn

- Menghitung biaya operasi yang meliputi biaya tetap dan biaya tidak tetap

\section{E. Analisis Data}

1. Menghitung produktivitas kerja dengan rumus (1) berikut:

$$
\begin{aligned}
& P=\frac{V}{T} \\
& \text { di mana : } P=\text { produktivitas } \operatorname{kerja~}\left(\mathrm{m}^{3} / \mathrm{jam}\right) \\
& \mathrm{V}=\text { Volume kayu yang dikeluarkan dari hutan }\left(\mathrm{m}^{3}\right) \\
& \mathrm{T}=\text { Waktu kerja efektif (jam) }
\end{aligned}
$$

2. Menghitung volume kayu digunakan rumus (2) berikut :

$$
\begin{aligned}
\mathrm{V}=1 / 4 \text { phi } \mathrm{D}^{2} \times & \mathrm{L} \ldots \ldots \ldots \ldots \ldots \ldots \ldots \\
\text { di mana: } \quad \mathrm{V} & =\text { Volume kayu }\left(\mathrm{m}^{3}\right) \\
\mathrm{D} & =\text { Diameter kayu }(\mathrm{cm}) \\
\mathrm{L} & =\text { Panjang }(\mathrm{m}) \\
\mathrm{Phi} & =\text { Konstanta }(3,14)
\end{aligned}
$$


3. Menghitung biaya operasi digunakan rumus (3) berikut :

$$
\mathrm{BOP}=\frac{\mathrm{BT}+\mathrm{BTT}}{\mathrm{P}}
$$

di mana :

$$
\begin{aligned}
& \mathrm{BOP}=\text { Biaya operasi }\left(\mathrm{Rp} / \mathrm{m}^{3}\right) \\
& \mathrm{BT}=\text { Biaya tetap }(\mathrm{Rp} / \mathrm{jam}) \\
& \mathrm{BTT}=\text { Biaya tidak tetap }(\mathrm{Rp} / \mathrm{jam}) \\
& \mathrm{P}=\text { Produktivitas kerja }\left(\mathrm{m}^{3} / \mathrm{jam}\right)
\end{aligned}
$$

4. Menghitung biaya tetap yang terdiri dari biaya penyusutan, bunga modal, dan biaya asuransi digunakan rumus (4) berikut :

Biaya penyusutan : $\mathrm{D}=\frac{\mathrm{M}-\mathrm{R}}{\mathrm{N} \times \mathrm{t}}$

di mana : $\mathrm{D}=$ Penyusutan (Rp/jam ); $\mathrm{M}=$ investasi alat $(\mathrm{Rp}) ; \mathrm{R}=$ nilai alat bekas $(20 \%)$ dalam rupiah; $\mathrm{N}=$ umur teknis alat (10 tahun); $\mathrm{t}=$ waktu kerja alat (1000 jam/tahun ).

Bunga modal :

$$
B=\frac{\frac{(M-R)(N+t)}{2}+R \times 0,0 p}{T}
$$

di mana : $\mathrm{B}=$ Bunga modal ( Rp/jam $), 0,0 \mathrm{p}=$ suku bunga/tahun $(12 \%)$

Biaya asuransi : $A=\frac{M \times(i+N)}{\text { N.t }} \times I / h$

di mana : $A=$ Biaya asuransi $(\mathrm{Rp} / \mathrm{jam})$; $\mathrm{i}=$ nilai asuransi per tahun dalam desimal; $\mathrm{h}=$ Jumlah jam kerja dalam satu tahun; $\mathrm{N}=$ umur pakai alat; $\mathrm{M}=$ Investasi alat $(\mathrm{Rp})$.

5. Menganalisis hasil wawancara dengan sejumlah 20 orang petani tradisional penduduk desa dalam bentuk kuesioner antara YA dan TIDAK, yaitu digunakan rumus (7) berikut :

$\mathrm{P}_{\mathrm{t}}+\mathrm{P}_{\mathrm{s}}=100 \%$ atau $\mathrm{P}_{\mathrm{t}}+\mathrm{P}_{\mathrm{s}}=1$, sehingga $\mathrm{P}_{\mathrm{t}}=\left(1-\mathrm{P}_{\mathrm{s}}\right)$

$\mathrm{P}_{\mathrm{t}}=$ Proporsi (persentase jawaban "Ya"); Ps = Proporsi (persentase jawaban "Tidak")

\section{HASIL DAN PEMBAHASAN}

\section{A. Hasil Produksi Koperasi Mitra Desa}

Yang dimasud Koperasi Mitra Desa ini adalah sebuah bentuk usaha kerja sama (kemitraan) antara warga desa sekitar hutan dengan HPH PT TRI dibidang pemanenan kayu bulat. Dilihat dari dokumen peta kerja, bahwa hutan produksi yang dipanen oleh koperasi itu berada pada wilayah kerja RKT 1999/2000 HPH PT TRI yang luasnya 
mencapai 500 ha. Sistem kerja sama usahanya yaitu, kayu bulat hasil Koperasi dijual kepada perusahaan HPH PT TRI dengan harga Rp 35.000/ $\mathrm{m}^{3}$.

Berdasarkan kesepakatan antara pimpinan HPH dengan ketua Koperasi Mitra Desa bahwa untuk melakukan pengeluaran kayu bulat atau penyaradan hasil tebangan digunakan traktor yang $90 \%$ fasilitasnya milik perusahaan $\mathrm{HPH}$ sedang $10 \%$ sisanya berupa upah insentif dibiayai oleh Koperasi Mitra Desa. Sedang untuk menebang pohon digunakan mesin gergaji rantai (chainsaw) yang 100\% fasilitasnya milik koperasi.

Bentuk perjanjian usaha bersama antara HPH dengan koperasi desa tersebut hanya didasarkan atas kepada saling percaya dan dilakukan secara ikrar lisan saja tanpa ada surat tertulis, akan tetapi jika terjadi sesuatu diluar perjanjian maka penyelesaiannya dilakukan secara musyawarah.

Hasil jumlah batang kayu bulat yang ditebang dan disarad oleh koperasi mencapai 51 batang dengan waktu tebang berlangsung selama 5 hari dan waktu menyarad selama 7 hari. Kualitas batang hasil tebangan $100 \%$ baik. Jenis kayu yang diproduksi antara lain meranti merah (Shorea leprosula), keruing (Dipterocarpus sp), jelutung (Dyera costulata), dan bangkirai (S. laevis Ridl). Untuk mengetahui produksi kayu bulat hasil kegiatan koperasi dapat dilihat pada Tabel 1.

Tabel 1. Produksi kayu bulat hasil Koperasi Desa

Table 1. Koperasi Desa log production

\begin{tabular}{|c|c|c|}
\hline Hari ke (Day) & Jumlah batang $($ Total log $)$ & Volume $\left(\mathrm{m}^{3}\right)$ \\
\hline 1 & 7 & 178.1 \\
2 & 7 & 109.1 \\
3 & 8 & 133.7 \\
4 & 8 & 93.5 \\
5 & 8 & 110.2 \\
6 & 7 & 140.6 \\
7 & 6 & 127.4 \\
\hline Jumlah (Total) & 51 & 892.9 \\
\hline
\end{tabular}

Hasil wawancara dengan 2 (dua) orang operator gergaji mesin dan satu orang operator traktor diketahui, bahwa untuk memperoleh kayu sebanyak 892,9 $\mathrm{m}^{3}$ masing-masing memerlukan waktu selama 5 hari dan 7 hari kerja. Dengan demikian dapat dihitung, bahwa dari sejumlah volume $892,9 \mathrm{~m}^{3}$ atau rata-rata per hari $127,5 \mathrm{~m}^{3}$ dengan waktu efektif dalam satu hari diasumsikan 4 jam, maka produktivitas kerja penebangan dan penyaradan masingmasing rata-rata mencapai $15,9 \mathrm{~m}^{3}$ dan $31,9 \mathrm{~m}^{3} / \mathrm{jam}$. Khusus pada kegiatan penyaradan, hasil pengukuran pada beberapa jalan sarad traktor dari kegiatan koperasi rata-rata menunjukkan panjang $304 \mathrm{~m}$. Dengan demikian produktivitas kerja penyaradan rata-rata mencapai $99 \mathrm{~m}^{3} \cdot \mathrm{hm} / \mathrm{jam}$.

Jika produktivitas penebangan di atas dibandingkan dengan hasil pengamatan Soẻnarno dan Idris (1990) yang telah dilakukan di beberapa HPH hasilnya adalah 21,7 $\mathrm{m}^{3} / \mathrm{jam}$. Dengan demikian, produktivitas penebangan menunjukkan lebih tinggi. Sementara itu pada penyaradan, jika dibandingkan dengan hasil penelitian Dulsalam dan Sukanda (1990) yang dilakukan di Jambi hasilnya menunjukkan produktivitas kerja traktor rata-rata $92,0 \mathrm{~m}^{3} / \mathrm{jam}$. Hasilnya ternyata berbeda, ini diduga karena jenis alat yang digunakan dan tingkat ketrampilan operator berbeda. 


\section{B. Biaya Operasi Penebangan dan Penyaradan}

Berdasarkan hasil wawancara dengan beberapa orang operator mesin gergaji rantai (chainsaw) dan traktor, diperoleh keterangan bahwa upah kerja menebang pohon adalah Rp $7.000,-/ \mathrm{m}^{3}$, sedang upah kerja menyarad kayu bulat dari petak tebangan ke TPn sebesar Rp $12.500,-/ \mathrm{m}^{3}$. Pembayaran upah kerja penebang pohon sepenuhnya ditanggung oleh Koperasi Mitra Desa, sedangkan upah kerja operator traktor $90 \%$ ditanggung oleh perusahaan HPH dan 10\% oleh Koperasi Mitra Desa.

Mesin gergaji rantai yang digunakan adalah merek STHILL tipe 07, kondisi mesinnya $80 \%$ (masih baik), diperkirakan harganya mencapai sekitar Rp 5.000.000,-. Sedang traktor yang digunakan sudah dioperasikan selama 10 tahun tetapi kondisinya $75 \%$ (masih baik). Pembelian mesin traktor diperkirakan pada waktu itu mencapai Rp 600.000 .000 ,- dengan kurs $1 \$$ US $=$ Rp 3.500,-. Dengan diketahuinya standar upah kerja dan harga mesin yang dioperasikan, maka secara rinci biaya operasi yang meliputi biaya tetap dan tidak tetap dapat dihitung seperti yang tertera pada Tabel 2 berikut.

Tabel 2. Biaya tetap dan biaya tidak tetap penebangan dan penyaradan kayu bulat Table 2. Fixed cost and variable cost of log felling and skidding operation

\begin{tabular}{|c|c|c|c|}
\hline No. & $\begin{array}{l}\text { Komponen kegiatan } \\
\text { (Activities component) }\end{array}$ & $\begin{array}{c}\text { Biaya mesin gergaji } \\
\text { rantai, Rp/jam } \\
\text { (Chainsaw cost, } \\
\text { Rp/hour) }\end{array}$ & $\begin{array}{l}\text { Biaya Traktor, } \\
\text { Rp/Jam } \\
\text { (Tractor cost, } \\
\text { Rp/Hour) }\end{array}$ \\
\hline A. & $\begin{array}{l}\text { Biaya tidak tetap } \\
\text { (Variable cost) }\end{array}$ & & \\
\hline 1 & Upah kerja (Salary) & 102.953 & 74.997 \\
\hline 2 & $\begin{array}{l}\text { Pemeliharaan alat } \\
\text { (Maintenance) } 10 \% \text { dari harga } \\
\text { pembelian ( } 0 \% \text { of investment) }\end{array}$ & 1.945 & 194.552 \\
\hline 3 & $\begin{array}{l}\text { Penggunaan Bahan bakar } \\
\text { minyak (Fuel) }\end{array}$ & 750 & 37.500 \\
\hline 4 & Penggunaan olie (Oil) & 750 & 75.000 \\
\hline B. & Biaya tetap (Fixed cost) & & \\
\hline 1 & Penyusutan (Depricsiation) & 450 & 316.800 \\
\hline 2 & $\begin{array}{l}\text { Bunga bank dan asuransi } \\
\text { (Interest and insurance) }\end{array}$ & 297 & 40.000 \\
\hline & Jumlah (Total) & 107.146 & 738.850 \\
\hline
\end{tabular}


Dengan melihat Tabel 2 di atas, biaya operasi penggunaan mesin gergaji rantai dan traktor masing-masing dapat dihitung sebagai berikut :

$$
\text { Biaya tetap + Biaya tidak tetap }
$$

1. Biaya operasi penebangan $=$

$$
\text { Produktivitas }
$$

$$
\begin{aligned}
& \text { Biaya operasi penebangan }=\frac{\mathrm{Rp} 107.146 / \mathrm{jam}}{15,9 \mathrm{~m}^{3} / \mathrm{jam}}=\mathrm{Rp} 6.721 / \mathrm{m}^{3} \\
& \text { Biaya operasi penebangan }=\operatorname{Rp~} 6.721 / \mathrm{m}^{3}
\end{aligned}
$$

2. Biaya operasi penyaradan $=\frac{\text { Biaya tetap }+ \text { Biaya }}{\text { Produktivitas }}$

$$
\begin{aligned}
& \text { Biaya operasi penyaradan }=\frac{\mathrm{Rp} 738.850 / \mathrm{jam}}{\mathrm{Rp} 99 / \mathrm{m}^{3}} \\
& \text { Biaya operasi penyaradan }=\operatorname{Rp} 7.463 / \mathrm{m}^{3}
\end{aligned}
$$

sehingga jumlah biaya operasi penebangan dan penyaradan menjadi $\mathrm{Rp} 14.184 / \mathrm{m}^{3}$.

Biaya operasi kayu bulat di atas ternyata lebih rendah, jika dibandingkan dengan hasil pengamatan yang pernah dilakukan oleh Efendi, $R$ dkk (1996) di Propinsi Sumatera Selatan $\left(\mathrm{Rp} 58.000 / \mathrm{m}^{3}\right)$. Hal itu terjadi karena yang di Sumatera Selatan, biaya operasinya itu meliputi seluruh kegiatan pemanenan hasil hutan yaitu mulai dari penebangan, penyaradan, pengulitan, pengangkutan sampai dengan kegiatan administrasinya. Sementara pengamatan yang dilakukan di Kalimantan Tengah hanya meliputi kegiatan penebangan dan penyaradan. Selain itu iuran untuk Dana Jaminan Reboasasi (DJR) dan iuran PSD belum dimasukan. Oleh karena itu biaya operasi pengeluaran kayu bulat yang dilakukan di PT TRI menjadi lebih rendah.

\section{Pendapatan Koperasi Mitra Desa}

Dengan harga jual kayu bulat sebesar Rp 35.000,- per $\mathrm{m}^{3}$ dari Koperasi Mitra Desa ke $\mathrm{HPH}$, maka dalam waktu 12 (dua belas) hari atau 2 mingu kegiatan operasi pemanenan tersebut, Koperasi Mitra Desa memperoleh pendapatan : 892,97 x Rp 35.000,- = Rp 31.235.950,-. Jika biaya pendapatan tersebut dikurangi oleh biaya investasi Koperasi dengan perhitungan :

1. Biaya investasi penebangan :

$$
\text { Rp } 107.146 \times 4 \text { jam } \times 5 \text { hari } \quad=\text { Rp } 2.142 .939
$$

2. Upah operator traktor :

$$
\begin{aligned}
\operatorname{Rp} 74.997 \times 10 \% \times 4 \text { jam } \times 7 \text { hari } & =\frac{\operatorname{Rp} 209.993,-}{\text { Jumlah: }}= \\
& =\operatorname{Rp~} 2.352 .932
\end{aligned}
$$


maka Koperasi Mitra Desa akan memperoleh dana : Rp 31.235.950,- - Rp 2.352.932= Rp 28.901.017,- (Dua puluh delapan juta sembilan ratus satu ribu tujuh belas rupiah).

Dana hasil Koperasi Mitra Desa sebesar Rp 28.901.017,-- tidak seluruhnya diperuntukan koperasi, tetapi dibagi-bagikan untuk kesejahteraan warga desa dan aparat yang besarnya masing-masing dapat dilihat pada Tabel 3 berikut.

Tabel 3. Distribusi dana hasil Koperasi Mitra Desa

Table 3. Income distribution of Koperasi Mitra Desa

\begin{tabular}{|c|c|c|c|c|}
\hline No. Pengeluaran (Payment) & $\begin{array}{l}\text { Satuan } \\
\text { (Unit) }\end{array}$ & Volume & $\begin{array}{c}\text { Pembagian } \\
\text { alokasi } \\
\text { (Allocation } \\
\text { income), } \\
\%\end{array}$ & $\begin{array}{c}\text { Jumlah } \\
\text { (Total), } \\
\text { Rp }\end{array}$ \\
\hline $\begin{array}{l}\text { 1. Kesejahteraan warga } \\
\text { (Community wellfare fee) } \\
\text { 2. Pengurus koperasi (Koperasi } \\
\text { board) } \\
\text { 3. Kepala desa (Village leader) } \\
\text { 4. Kecamatan (District } \\
\text { services) } \\
\text { 5. Kepolisian (Police sector) } \\
\text { 6. Koramil (Army distric) } \\
\text { 7. Administrasi koperasi } \\
\text { (Administration) } \\
\text { 8. Kas dusun (Village fee) }\end{array}$ & $\begin{array}{l}\text { KK } \\
\text { Orang } \\
\text { Orang } \\
\text { Orang } \\
\text { Orang } \\
\text { Orang } \\
\text { Orang } \\
\text { Orang } \\
\end{array}$ & $\begin{array}{l}210 \\
11 \\
1 \\
1 \\
1 \\
1 \\
\text { Paket } \\
\text { Paket }\end{array}$ & $\begin{array}{c}34 \\
29 \\
5,5 \\
7 \\
5,5 \\
5 \\
4,5 \\
4,5\end{array}$ & $\begin{array}{l}9.827 .345 \\
8.382 .294 \\
1.589 .555 \\
\\
2.023 .071 \\
1.589 .555 \\
1.445 .045 \\
\\
1.300 .545 \\
1.300 .545 \\
\end{array}$ \\
\hline Jumlah (Total) & & & 100 & 28.901 .017 \\
\hline
\end{tabular}

Sumber (Source) : Laporan Keuangan Koperasi Mitra Desa, 2000

(Finacial report of Koperasi Mitra Desa, 2000)

Dari Tabel 3 di atas terlihat, bahwa biaya yang disalurkan kepada masyarakat desa mencapai $34 \%$, pengurus Koperasi $29 \%$, kas desa $4,5 \%$, administrasi koperasi $5 \%$ dan aparat $27 \%$.

Sepintas keuntungan Koperasi Desa yang terbesar adalah untuk warga desa, namun setelah dianalisis yang diterima per kepala keluarganya hanya $0,16 \%$, jadi sangat kecil dibandingkan dengan yang lain. Tetapi sebaliknya bagi aparat pemerintah dan pengurus Koperasi walaupun persentasenya kecil tetapi karena jumlah anggotanya sedikit, maka nominal per kepala keluarga yang diterima menjadi besar. Dengan demikian dapat disimpulkan, bahwa dengan adanya usaha kemitraan tersebut masyarakat desa sekitar hutan tidak bertambah sejahtera, tidak ada perubahan yang berarti, karena rakyat desa itu hanya dijadikan alasan untuk mencari untung bagi dan aparat.

kepentingan beberapa orang pihak yang menerima untung terbesar adalah pengurus

Namun demikian, hikmah dari adanya dana insentif dari perusahaan HPH melalui usaha kemitraan, kegiatan ilegal loging yang dilakukan oleh masyarakat dapat dikurangi dan masyarakat desa tersebut cenderung mulai bisa diatur, misalnya perambahan liar untuk lahan petani menjadi bisa di lokalisir sehingga mempermudah pengawasan. 
Dalam rangka rehabilitasi lahan kritis dan pencegahan bahaya kebakaran hutan, hasil wawancara dengan sejumlah 20 (dua puluh) orang petani tradisional masyarakat desa sekitar hutan, $100 \%$ menyatakan siap membantu HPH dan program pemerintah.

Selanjutnya, jika biaya pembelian kayu dari Koperasi Mitra Desa oleh HPH tersebut diperhitungkan dengan kewajiban $\mathrm{PMDH}$ (diluar kegiatan koperasi) khususnya yang dikeluarkan untuk pemberdayaan masyarakat desa sekitar hutan, seperti : a) Untuk kegiatan pendidikan dan pelatihan pertanian, b) pemberian bibit, c) pembangunan jalan dan prasarana jalan termasuk fasilitas sosial, maka tidak mustahil bahwa selama ini sebenarnya HPH telah memberikan konstribusi cukup besar kepada masyarakat desa sekitar hutan, termasuk kepada semua aparatnya itu. Akan tetapi karena sistem Koperasi Mitra Desa ini merupakan wujud dari tuntutan masyarakat lokal, sementara PMDH itu merupakan pesanan dari pusat, maka tidak bisa dipungkiri jika bantuan atau program PMDH itu oleh masayarakat lokal kurang ditanggapi. Menurut anggapan mereka cukup wajar jika perusahaan HPH melakukan pembangunan desa melalui program PMDH di daerahnya, sebab kekayaan hutan yang dikelola oleh HPH berada di wilayahnya. Sebagai kompensasinya, sistem kemitraan dengan masyarakat desa sekitar hutan bersama HPH adalah kewajiban yang tidak boleh ditawar-tawar lagi, sehingga jika tidak dilakukan oleh HPH maka sanksinya dari masyarakat desa sekitar hutan cukup berat dan sangat beresiko tinggi. Oleh karena itu, agar HPH dapat terus berjalan dan keamanan usahanya terjamin, maka sistem usaha kemitraan dengan Koperasi Desa dan proyek PMDH harus terus dilaksanakan tanpa harus merugikan kedua belah pihak.

Atas dasar uraian masalah tersebut di atas, maka secara garis besar dapat disimpulkan, bahwa sebenarnya secara moral bagi para pengusaha lokal dengan adanya usaha kemitraan di bidang pemanenan kayu bulat ini dapat merupakan suatu perubahan besar dalam sistem management kehutanan nasional, karena secara tidak langsung masyarakat lokal sudah mulai merasakan adanya keadilan dalam menikmati keberadaan hutan alam produksi dibandingkan dengan sebelum zaman reformasi, walaupun secara materi belum memadai bagi seluruh warga desa. Selain itu antara masyarakat desa sekitar hutan dengan pemilik konsesi mulai peduli terhadap iklim kemitraan yang kondusif dalam pengelolaan hutan alam produksi walaupun modelnya masih tersendat-sendat tetapi secara pelan-pelan mungkin nantinya ke depan akan berjalan lancar. Dan yang paling penting sekarang nampaknya mulai tumbuh saling kepercayaan antara pengusaha besar dengan pengusaha kecil di bidang pemanenan hasil hutan alam produksi.

\section{KESIMPULAN DAN SARAN}

1. Produktivitas kerja mesin gergaji rantai rata-rata $15,9 \mathrm{~m}^{3} / \mathrm{jam}$ sedang traktor ratarata $99 \mathrm{~m}^{3} \cdot \mathrm{hm} / \mathrm{jam}$.

2. Biaya operasi pengeluaran kayu bulat mencapai $\mathrm{Rp} 14.227,35 / \mathrm{m}^{3}$ yang terdiri dari biaya penebangan mencapai $\mathrm{Rp} 6.721,8 / \mathrm{m}^{3}$ dan biaya penyaradan sebesar $\mathrm{Rp}$ $7.463,1 / \mathrm{m}^{3}$. Pendapatan dana Koperasi Mitra Desa mencapai Rp 28.901.017 yang semuanya itu dibagikan ke warga masyarakat desa sekitar hutan sebesar $34 \%$, pengurus Koperasi $29 \%$, kas dusun $4,5 \%$, dan aparat $27 \%$.

3. Dengan adanya sistem usaha kemitraan antara Koperasi Desa dengan HPH, maka pengusaha lokal sudah mulai merasakan adanya keadilan dalam menikmati keberadaan hutan alam produksi. 
4. Agar lebih adil dalam pembagian hasil koperasi sebaiknya alokasi untuk aparat dan pengurus koperasi persentasenya tidak terlalu besar.

5. Dalam mengelola hutan alam produksi agar kelestarian fungsi produksi, ekologis dan sosial tetap terjamin, maka antara HPH dengan Koperasi Mitra Desa perlu dibuat surat kesepakatan bersama yang jelas dan tegas.

\section{DAFTAR PUSTAKA}

Anonim. 1984. Teknik dasar pemilikan alat-alat besar. Technical Consulting Departement PT United Tractor. Jakarta. Tidak dipublikasi.

1999. Izin pemanfaatan kayu : Inikah biang kerusakan hutan. Republika. Jakarta. Koran Jakarta.

, 2001. Laporan Keuangan Koperasi Mitra Desa. Desa Juking Sopan, Muara Teweh, Kalimantan Tengah. Tidak dipublikasi.

-, 2001. Laporan bulanan pelaksanaan PMDH PT Tanjung Raya Intiga. Muara Teweh, Kalimantan Tengah.

Dulsalam dan Sukanda. 1989. Produktivitas kerja traktor caterpilar D7G di suatu perusahaan HPH di Jambi. Jurnal Penelitian Hasil Hutan 6(6): 368 - 372. Pusat Litbang Hasil Hutan. Bogor.

Idris, M.M. dan Soenarno. 1991. Produktivitas dan beban kerja operator gergaji rantai pada kegiatan penebangan pohon berbanir tinggi di hutan alam di Kalimantan Tengah. Jurnal Penelitian Hasil Hutan 9(2): 45 - 52. Pusat Litbang Hasil Hutan. Bogor. 